\title{
Ultrasound Elastography-A Useful Tool in Assessment of Diffuse Liver Disease
}

\author{
Praveen Kumar John ${ }^{1}$, Chaithra T K ${ }^{2}$, Chidananda Murthy $\mathrm{M}^{3}$, Francis N. P. Monteiro ${ }^{4}$ \\ Associate Professor, Department of Radio-Diagnosis, A.J. Institute of Medical Sciences and Research Centre, NH 17, Kuntikana, Mangalore -575004, ${ }^{2}$ Consultant \\ Radiologist, Siddaganga Hospital and Diagnostic Centre, Tumkur, ${ }^{3}$ Assistant Professor, Department of Radio-Diagnosis, A.J. Institute of Medical Sciences and \\ Research Centre, NH 17, Kuntikana, Mangalore -575004, ${ }^{4}$ Professor, Department of Forensic Medicine \& Toxicology, A.J.Institute Of Medical Sciences And \\ Research Centre, Nh 17, Kuntikana, Mangalore -575004.
}

\section{Abstract}

Background: Diffuse liver diseases are commonly encountered in clinical practice and on radiological imaging .Early detection and accurate diagnosis are extremely important in the definitive management of such patients. Ultrasonography is the widely used and the first line of radiological investigation in patients suspected with diffuse liver disease. Ultrasound elastography is a recent advance in the field of ultrasonography which has reportedly improved the accuracy in the assessment of severity of liver fibrosis in diffuse liver diseases. Objectives: 1.To evaluate the role of elastography for evaluation of diffuse liver disease. 2. To evaluate the sensitivity and specificity of sonoelastography in detection and characterisation of diffuse liver disease and correlation with other clinical diagnostic modalities and histopathology as gold standard. Subjects and Methods: Study was conducted from from August 2014 to August 2016.Based on inclusion and exclusion criteria, 30 cases of diffuse liver diseases were included in the study.The ultrasound and ultrasound elastography were done in the AJ Institute of Medical Sciences. These 30 cases were subjected to FNAC/Tru-cut Biopsy for the confirmation of ultrasound and ultrasound elastography finding and establishment of final diagnosis. Results: In our study of 30 cases of diffuse liver lesions ,after Metavir scoring $13 \%$ were $\mathrm{F} 1,16 \%$ were $\mathrm{F} 2,23 \%$ were $\mathrm{F} 3$, and $46 \%$ were F4.The sensitivity and specificity for F1 and F2 were $100 \%$ and $100 \%$, for F3 was $71 \%$ and $91 \%$, for F4 85 and $87 \%$.the mean cut off value for the cirrhosis was found to be 18kPa. Conclusion: Ultrasound elastography is a recent advance in the field of ultrasound, which is a non invasive method in assessment of severity of liver fibrosis and end stage cirrhosis.

Keywords: Ultrasound, elastography, liver, fibrosis, cirrhosis

Corresponding Author: Dr. Chidananda Murthy M, Associate Professor, Department of Radiodiagnosis, A.J. Institute of Medical Sciences And Research Centre, NH 17, Kuntikana, Mangalore -575004.

Received: October 2018

Accepted: November 2018

\section{Introduction}

Ultrasound imaging plays a vital role in the diagnosis, monitoring and therapeutic treatment of chronic liver disease. However conventional ultrasound does not give any objective criteria for better characterisation and provide information regarding tissue stiffness, since many diseases affect and change the tissue stiffness like in liver fibrosis.

Elastography is a recent technique that generates images and values based on the tissue stiffness. Apart from liver, this method has been used to evaluate other organs like breast, thyroid

Presently the different ultrasound methods available to assess liver stiffness which have been published include transient elastography (TE) (Fibroscan strain elastography and shear wave elastography imaging. ${ }^{[1-6]}$ Other techniques include 2D-SWE(Supersonic) and 3D-SWE(shear wave elastography\}. ${ }^{[7,8]}$

Ultrasound elastography of liver has been used to assess the liver tissue stiffness (elasticity) in chronic liver disease, ${ }^{[9]}$ grading of fibrosis in cirrhosis and in characterisation of focal liver masses. ${ }^{[10,11]}$

Liver fibrosis has become a major public health problem because Liver fibrosis is a common pathway for several liver pathologies like Viral (hepatitis B virus (HBV), hepatitis C (HCV), human immunodeficiency virus (HIV)-HCV co-infection), autoimmnune, hereditary, metabolic, toxin -mediated liver disease, non alcoholic steato-hepatitis (NASH), non alcoholic fatty liver disease (NAFLD)which can result in hepatocellular dysfunction, expansion of extracellular matrix ,distortion of liver architecture ,portal hypertension and final end stage cirrhosis. $^{[12]}$

Different levels of fibrosis exist in practice in cirrhosis and chronic liver parenchymal disease. Hence staging of liver fibrosis is essential for management purpose. This staging of liver fibrosis is done on histological score. Types of fibrosis staging are the histology activity index (HAI), the Ishak modification of the HAI score and the METAVIR score. $^{[13]}$

The METAVIR score is the system used in this work and 


\section{John et al; Ultrousaund Elastagraphy}

represent a semi-quantitative classifications system and scores both necroinflammatory changes. The activity score is divided according to the intensity of necroinflammatory lesions. The fibrosis score is assessed on a five point scale. F0 (no fibrosis), F1(portal fibrosis without septa :minimal fibrosis),F2(portal fibrosis with a few septa :moderate fibrosis or clinically significant fibrosis ), F3(septal fibrosis with many septa but no cirrhosis:severe fibrosis) F4(cirrhosis). ${ }^{[13]}$

\section{Subjects and Methods}

A cross section study was conducted for a period of 2 years from August 2014 to August 2016

Based on the inclusion and exclusion criteria, 30 cases of diffuse liver disease that are diagnosed by ultrasound were included in the study. The ultrasonography and ultrasound elastography examination was done in the department of Radiology A J Institute of Medical sciences. The 30 cases which were found to have diffuse liver diseases with high elasticity on ultrasound elastography were subjected to blood investigations, CECT abdomen and then FNAC for histopathological staging of liver fibrosis for confirmation of ultrasound findings and final confirmation .

\section{Inclusion criteria:}

Patients of clinically suspected diffuse liver lesion at primary presentation or detected on ultrasonography were enrolled for the study.

\section{Exclusion criteria}

1. Patients in whom final confirmatory diagnosis could not be established were excluded.

2. Poor compliance of patient or inablility to hold their breath.

\section{Equipment}

Liver ultrasonography for diffuse liver diseases was performed using convex broadband probe(C5-1) Ultrasound Shear wave elastography was done using $1-5 \mathrm{Mhz}$ convex transducer of EPIC 5 machine from Philips.

\section{Positioning of the Patient}

Patients in fasting status are placed in supine position, with right arm in maximum abduction to make the right hypochondrium accessible and to increase intercostal space.

The maximum depth penetration is $8 \mathrm{~cm}$ and the size of the region of interest is $10 \times 5 \mathrm{~mm}$.Patient is asked to stop breathing for a moment (only breath holding) and then measurements are obtained from the right lobe of liver .with the transducer kept in the intercostal space almost at the midaxillary line .Few measurements are also taken from the left lobe.

Minimum of 10 measurements were taken in kilopascals in case of diffuse liver diseases and then mean was obtained.

\section{LaboratoryAnalysis included}

ALT, AST, GGT, Bilirubin, AFP, HCV, HBV, HIV, Serum cholesterol, platelets

\section{Cytological Examination}

FNA was performed with 18/20/22 G (gauge) needle/tru cut biopsy with 16/18 G.cytological results were reported according to METAVIR score for grading of liver fibrosis [F0-F4]

\section{Results}

Total of 30 patients who were found to have diffuse liver diseases with high elasticity on ultrasound elastography were evaluated .Of the 30 patients $8(26 \%$ )were below 40 years, $11(36 \%)$ were between 41 to 50 and 11(36\%) were above 50 years. Of the 30 patients, $20(66 \%)$ were males and $10(33 \%)$ were females. As the amount of alcohol consumption is more common in men than women, which leads to liver disease and cirrhosis in late stage, this is probably the reason for the increased incidence in men.

Metavir fibrosis scoring is the Histopathological scoring for grading of fibrosis which includes, F0 (no fibrosis), F1 (portal fibrosis without septa: minimal fibrosis), F2 (portal fibrosis with a few septa: moderate fibrosis or clinically significant fibrosis), F3 (septal fibrosis with many septa but no cirrhosis:severe fibrosis) F4 (cirrhosis).

In our study, out of 30 cases, 4 (13\%) were F1, 5(16\%) were F2, 7(23\%) were F3, 14(46\%) were F4 based on metavir scoring.

\begin{tabular}{|c|c|c|}
\hline \multicolumn{3}{|c|}{ Table 1: Incidence of Fibrosis scoring (metavir score) } \\
\hline Score & Frequency & Percentage \\
\hline F1 & 4 & 13.5 \\
\hline F2 & 5 & 16.7 \\
\hline F3 & 7 & 23.3 \\
\hline F4 & 14 & 46.7 \\
\hline Total & 30 & 100.0 \\
\hline
\end{tabular}

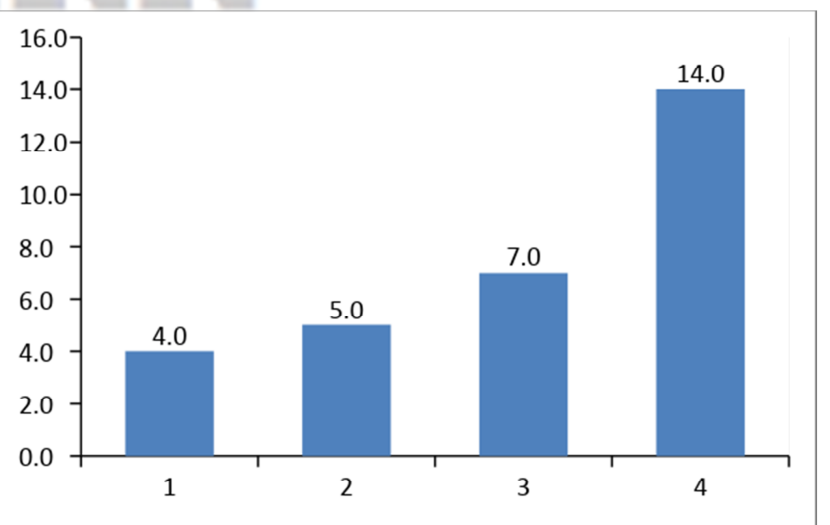

Graph 1: Bar diagram depicting the frequencies of different stages of fibrosis

Table 5: Elastography grading with correlation to metavir score (Histopathology scoring)

\begin{tabular}{|c|c|c|c|}
\hline $\begin{array}{c}\text { Metavir } \\
\text { Score }\end{array}$ & Frequency & $\begin{array}{c}\text { Elastography } \\
\text { Values(kPa) }\end{array}$ & $\begin{array}{c}\text { Cut off value } \\
\text { Considering } \\
\text { median (kPa) }\end{array}$ \\
\hline F1 & 4 & $5.6-7.0$ & 6.5 \\
\hline F2 & 5 & $8.7-9.2$ & 9.8 \\
\hline F3 & 7 & $11.2-13.8$ & 12.9 \\
\hline F4 & 14 & $14.1-33.0$ & 18.0 \\
\hline
\end{tabular}


[Table 5] depicts the the cut off range and the cut off mean values in the different fibrosis stages.

Of the 7 cases in F3, 5 were correlating with the histopathology(Metavir) scoring and had cut off elastography range value between 11.2-13.8 range .2 of them had values in the cirrhotic range the reason for high elastography value could be due to values obtained at the end of expiration, food intake or non-fasting state which can increase the liver stiffness and thus the elasticity value .

Of the 14 cases in F4 cirrhosis, 12 were correlating with the histopathology (Metavir) scoring and had cut off elastography range value between $14.1-33 \mathrm{kPa}$. 2 of them had elasticity value less than $14.1 \mathrm{kPa}$.the probable reason could be due to values obtained during the patient respiration.

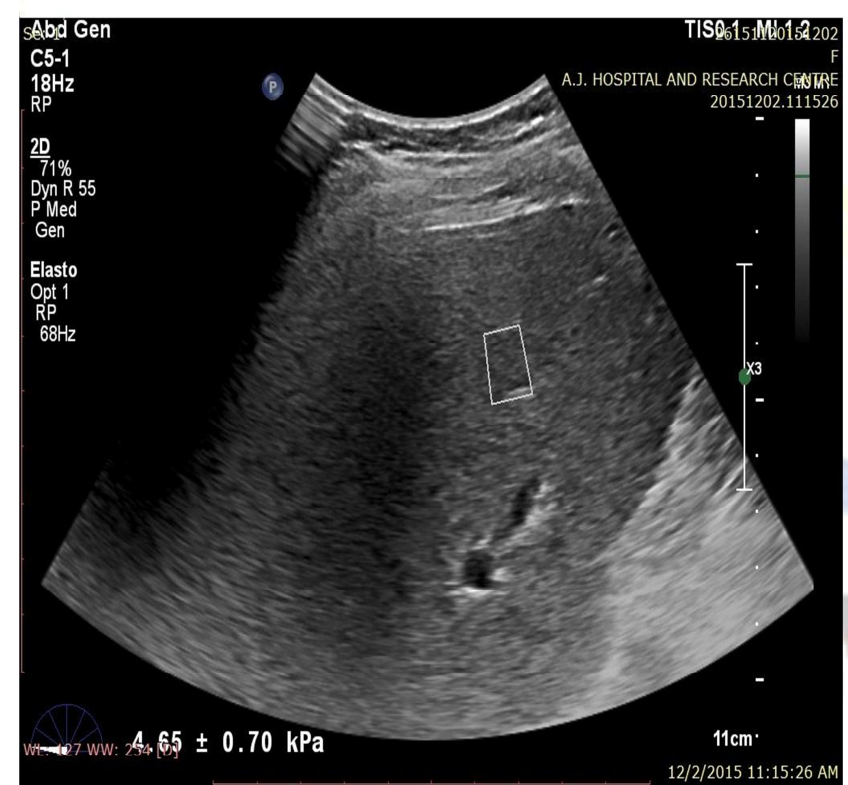

Figure 1: Normal liver with mean elastography value of 4.6Kpa

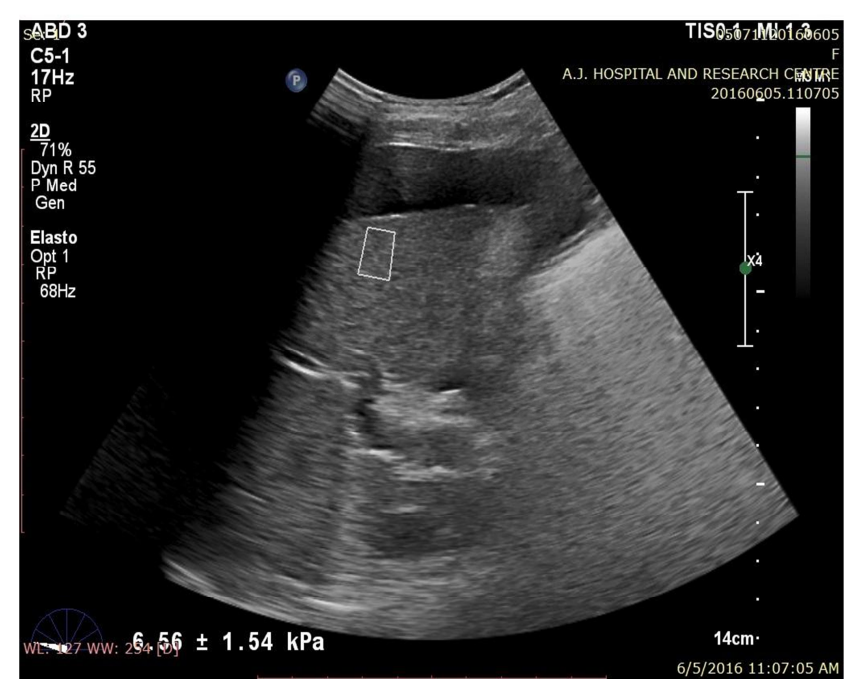

Figure 2: Chronic liver disease in Hepatitis B with mean

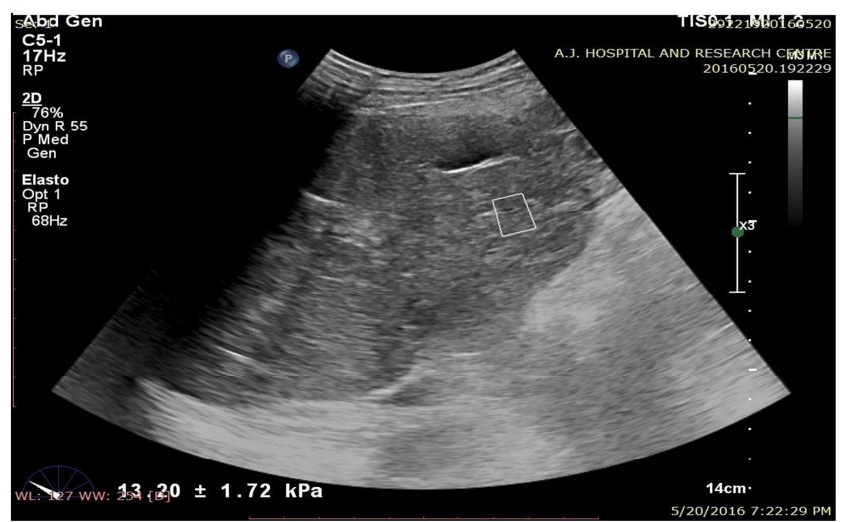

Figure 3: Cirrhotic elastography value of $13 \mathrm{kPa}$

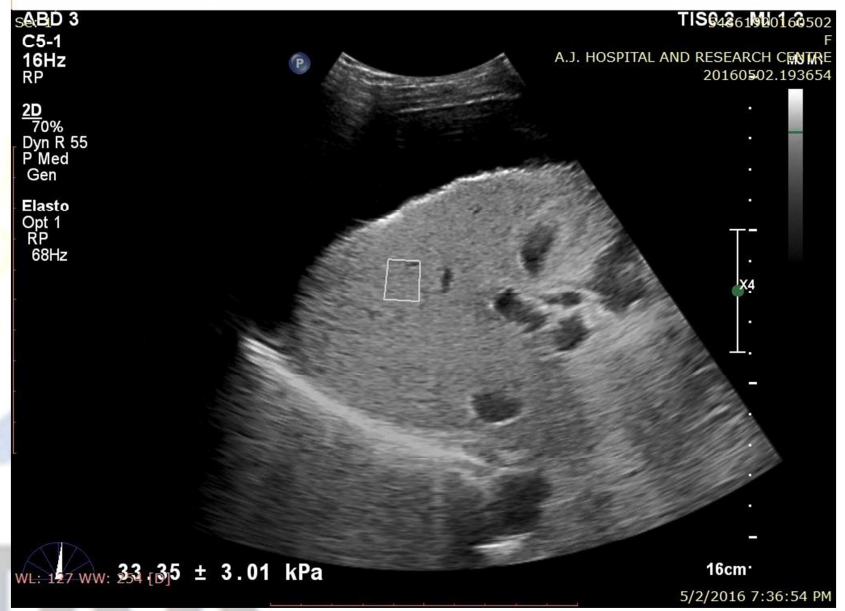

Figure 4: Cirrhosis of liver with mean elastography value of $33 \mathrm{kPa}$

\section{Discussion}

Various investigations are used for evaluating diffuse liver diseases and focal liver lesions which includes Biochemical investigations, Radiological investigations like ultrasonography, CT and MRI .The gold standard is the Histopathological examination which requires liver biopsy. It is an invasive procedure which is disadvantage. Hence, noninvasive investigation like ultrasound elastography can be used to assess the severity of disease progression to cirrhosis in case of liver diseases like chronic hepatitis B, chronic hepatitis c infection, NASH, NAFLD , alcohol liver disease and other causes of cirrhosis.

In our study, no significant correlation was noted in age wise distribution of diseases. However significant corelation was found in sex wise distribution of diseases. The incidence of cirrhosis is more common in males $(66 \%)$ than in females $(33 \%)$ probably due to the increased alcohol consumption in male group which is an important risk factor for the development of cirrhosis.

In the study conducted by Tsochatzis EA et al. In the case 
of cirrhosis (F4), the results showed a cut-off of $15.08 \mathrm{kPa}$ with a sensitivity of $84 \%$ and specificity of $95 \%$. Another meta-analysis of 40 eligible studies showed that the summary sensitivity and specificity were $78 \%$ and $80 \%$ for significant fibrosis, and $83 \%$ and $90 \%$ for cirrhosis. 58 In our study of diffuse liver disease, out of 30 cases, 14 cases had cirrhosis with the mean cut off value of $18 \mathrm{kPa}$. With a sensitivity of $85 \%$, specificity of $87 \%$, positive predictive value (PPV) of $85 \%$ and negative predictive value of $87 \%$.

Ioan Sporea et al conducted prospective study in 383 patients with or without hepatopathies, in which liver stiffness (LS) was evaluated by means of TE (transient elastography) and 2D-SWE (shear wave elastography). They found LS cut-off values assessed by 2D-SWE for predicting different stages of liver fibrosis were $: F \geq 1$ : $>7.1 \mathrm{kPa} ; \mathrm{F} \geq 2:>7.8 \mathrm{kPa} F \geq 3:>8 \mathrm{kPa}$ and for $\mathrm{F}=4$ : $>11.5 \mathrm{kPa} .^{[14]}$

In a study done by the Guibal et al in 170 patients, SWE sensitivity and specificity were respectively $85.1 \%$ and $82.7 \%$ ( $\geq$ F2), $88.9 \%$ and $90.3 \%$ ( $\geq$ F3), $93.3 \%$ and $98.3 \%$ (F4). In the subgroup study, a significant correlation was found between the percentage of fibrosis and stiffness as assessed by SWE. ${ }^{[15]}$

In our study, the sensitivity and the specificity were $100 \%$ and $100 \%,(\quad \mathrm{~F} 1), 100 \%$ and $100 \%(\mathrm{~F} 2), 71 \%$ and $91 \%$ (F3), $85 \%$ and $87 \%(\mathrm{~F} 4)$.

$\mathrm{Xin}$ wu cui et al found in chronic viral infection $\mathrm{HCV}$ related cirrhosis liver stiffnes value $>6.8-7.6 \mathrm{kpa}$ are indicative of significant fibrosis using the gold standard liver biopsy, and the cut off value for predicting complete cirrhosis $(\mathrm{F}=4)$ range between 11.0 and $13.6 \mathrm{kpa}$.and optimal cut of value for diagnosis HBV related cirrhosis were between 9.0 and $11.0 \mathrm{kpa}$. They did meta -analysis including 40 studies, the polled sensitivity and specificity of TE was $79 \%$ and $78 \%$ for the diagnosis of significant fibrosis; $82 \%$ and $86 \%$ for the diagnosing severe fibrosis ; and $83 \%$ and $89 \%$ for the diagnosis of liver cirrhosis and concluded that transient elastography is able to distinguish mild fibrosis from advanced liver fibrosis and cirrhosis. ${ }^{[16]}$

\section{Conclusion}

Ultrasound is a simple, safe, repeatable, cost effective modality of imaging and also the first line of investigation of choice in suspected case of diffuse liver lesions.

Though liver biopsy (LB) is the gold standard method for the assessment of the liver fibrosis, it is an invasive procedure, and fibrosis is unevenly distributed. The specimen obtained in liver biopsy is roughly only $1 / 50000$ of the total liver volume resulting in false negative samples and there is high inter and intraobserver variability. Considering these limitations of liver biopsy in daily practice, noninvasive methods for the evaluation of liver disease severity represent an alternative.

Elastography with ultrasound is a noninvasive technique for the assessment of liver fibrosis in chronic hepatitis B and C, cirrhosis, NASH, NAFLD . This also helps in follow up and assessing the progress.

\section{References}

1. Talwalkar JA,Kurtz DM ,Schoenleber SJ,West CP,Montori VM.Ultrasound-based transient elastography for the detection of hepatic fibrosis:systematic review and metaanalysis.clin GastroenteroHepatol 2007;5:1214-1220.arr RG.US elastography: applications in tumors.In:Luna,Vilanova JC,Rossi SE,et al,editors.Functional imaging in oncology.New York:Springer Heidelberg; 2014 p:459-86.

2. Friedrich-Rust M,Ong MF,Martens S,SarrazinC,BojungaJ,Zeuzem S,et al.Performance of transient elastography for the staging of liver fibrosis:a meta-analysis.Gastroenterology 2008;134:960-974.osgrove D,Piscaglia F, Bamber J,et al.EFSUMB guidelines and recommendations on the clinical use of ultrasound elastography.Part 2:clinical applications.Ultraschall Med 2013;34(3):238-53.

3. Friedrich -Rust M,Ong MF,Herrmann E,Dries V,Samaras p,Zeuzem S,et al.Real -time elastography for noninvasive assessment of liver fibrosis in chronic viral hepatitis.AJR Am j Roentegenol 2007; 188:758-764.

4. Havre RF,Elde E,Gilja OH,Odegaard S,Eide GE,Matre k,et al.Freehand real-time elastography:impact of scanning parametrers on image quality and in invitro intra and interobserver validations .Ultrasound Med Biol 2008;34:1638-1650.

5. Sporea I,Sirli R,Bota S,Popescu A,Sendroiu M,Jurchis A.Comparative study concerning the value of acoustic radiation force impulse elastography (ARFI)in comparision with transient elastography (TE) for the assessment of liver fibrosis in patients with chronic hepatitis B and C .Ultarsound Med BioL 2012;38:1310-1316.

6. Lupsor M,Badea R,Stefanescu H,Sparchez Z,Branda H,Serban A,et al.Performance of a new elastographic method (ARFI technology)compared to unidimensional transient elastography in the noninvasive assessment of chronic hepatitis c.Preliminary results.J Gastrointenstin I iver Dis 2009; 18:303-310

7. Bavu E,Gennission JL,Couade M,Bercoff J,Mallet V,Fink M,et al.Noninvasive in vivo liver fibrosis evaluation using supersonic shear imaging:a clinical study on 113 hepatitis $\mathrm{C}$ virus patients.Ultrasound Med Biol 2011;37:1361-1373.

8. Muller M,Genission JL,Deffieux T,Tanter M,Fink M.Quantitative viscoelasticity mapping of human liver using supersonic shear imaging :preliminary in vivo feasibility study.Ultrasound Med Biol 2009;35:219-229

9. Castera L.Non invasive methods to assess liver disease in patients with hepatitis B or C .Gastroenterology 2012;142(6):1293e4-302e4.

10. Wai CT,Greenson JK,Fontana RJ,Kalbfieisch JD,Marrero JA,Conjeevaram HS, et al.A simple non invasive index can predict both significant fibrosis and cirrhosis in patient 2 ith chronic hepatitis C.Hepatology 2003;38(2):518-216

11. Assy N,Nasser G,Djibre A,Beniashvili Z,Elias S,Zidan J characteristics of common solid liver lesions and recommendations for diagnostic workup.World Gastroenterology 2009;15:3217-3227.

12. N. Frulio,H.Trillaud, Ultrasound elastography of liver ,Diagnositic imaging and interventional imaging 2013;94:515-534

13. Macarini L, Stoppino L P. Practical Management of Chronic Viral Hepatitis, RadiologicAssessment of Liver Fibrosis - Present and Future: Chapter 5. 2013; 112

14. Ioan spores,simona Boat,Oana Gradinaru-Tascau,Roxana Airline,Alina popescu,et all are the cut -off values of 2D shear wave elastography liver stiffness measurements predicting different stages of liver fibrosis,considering transient elastography(TE) as the reference method European Journal of Radiology,Volume 83,Issue 3, March 2014;pages e118-e122.

15. Guibal ,G.Renosi,A.Rode,J.Y.Scoazec, O.Guillaud,L.Chardon,et all.Lefort shear wave elastography:An accurate technique to stage liver fibrosis in chronic liver disease,Diagnostic and interventional Imaging, Volume 97, Issue 1,January 2016;pages 91-99.

16. Xin-Wu Cui,Mireen Friedrich -Rust,Chiara De Milo,AndreIgnee,et all.liver elastography,comments on EFSUMB elastography guidelines World Gastroenterol 2013;19:6329-6347. 
Copyright: (C) the author(s), publisher. Asian Journal of Medical Radiological Research is an Official Publication of "Society for Health Care \& Research Development". It is an open-access article distributed under the terms of the Creative Commons Attribution Non-Commercial License, which permits unrestricted non-commercial use, distribution, and reproduction in any medium, provided the original work is properly cited.

How to cite this article: John PK, Chaithra TK, Murthy MC, Monteiro FNP. Ultrasound Elastography-A Useful Tool in Assessment of Diffuse Liver Disease. Asian J. Med. Radiol. Res. 2018;6(2):31-35.

DOI: dx.doi.org/10.21276/ajmrr.2018.6.1.9 